\title{
The Supporting Effective Teaching Project: 1. Factors Influencing Student Success in Inclusive Elementary Classrooms
}

\author{
Anne Jordan \\ University of Toronto (OISE)
}

\begin{abstract}
The Supporting Effective Teaching project commenced in the early 1990s with studies of how classroom teachers work with students with special educational needs included in their elementary classrooms. Over the ensuing 20 years, the project team prepared and tested a model of the factors that influence student outcomes in inclusive classrooms, with emphasis on the beliefs and practices of regular elementary classroom teachers and on their sense of responsibility for meeting the diverse learning needs of their students. This article provides an overview of the SET project to show how the model evolved and to bring together the findings that were published previously. It takes a different tack from previous papers in that it begins at the most surprising outcome, the importance of teaching practices. Arguably the most significant empirical finding from the project is that teachers who believe it is their responsibility to include students with special education needs are more effective practitioners for all their students. The article then traces the factors that contribute to this finding: quality of instruction, teacher beliefs about ability and disability, teacher beliefs about learning and instruction, and school context. The purpose is to present a comprehensive review of the project findings in the context of recently published research on inclusion.
\end{abstract}

This paper reviews the various sources of empirical evidence contained in the project. It begins at the point that showed how teachers' instructional practices in inclusive elementary classrooms vary in providing students with the opportunity to learn, not only 
for students with special education needs $(\mathrm{SEN})^{1}$ but for all students. The differences in practices are then related to the characteristics and impact of instruction from the perspective of learners, and to differences in teachers' beliefs about ability and disability, and about learning and instruction. The purpose is to present a comprehensive review of the project beginning with the finding that some teachers in inclusive classrooms are more effective practitioners with all their students than others, and to situate this in the context of recently published research on inclusion.

The Supporting Effective Teaching project began in the early 1990s. In one study (Jordan, Lindsay \& Stanovich, 1997; Lindsay, 1995), three regular classroom teachers who held positive beliefs about including students with SEN structured their lessons so that they spent copious amounts of instructional time with their students during seat work. Compared to six other teachers who were more skeptical about inclusion, there was little non-academic talk, but a focus on lesson-related talk that elaborated students' thinking: questioning and providing guidance, and generally "scaffolding" instruction with individual students and small groups. As a result, these teachers were able to achieve higher levels of cognitive engagement with their students, both with and without SEN. Teachers calibrated their lesson material and instruction to different levels of understanding and mastery of their students.

Teachers who elaborated student thinking allocated more instructional time to students with SEN than to other students. Although this seems to indicate that the presence of students with SEN might have been detracting from the instructional time available to students who were not designated as having SEN, in fact this was not the case. Even students who were typically achieving received more academic instruction than students in the other classrooms, and at deeper levels of cognitive engagement. These teachers had developed a teaching style and a classroom structure that adapted the content and instructional approach for every student.

This study suggested that not only quantity but also quality of instruction varied from classroom to classroom and by large amounts, especially for students with SEN. Furthermore, instructional practices had an impact on the opportunity to learn for all students, both with and without SEN. As a small-scale study, however, the findings raised many questions.

At this early stage of the project there was considerable disagreement in the literature about the efficacy of inclusion (Kauffman, 1981; Kauffman \& Hallahan, 2005). There was also ample evidence that teachers differed in their beliefs about inclusion, the nature of ability and disability, and about their roles and responsibilities for meeting the needs of their students, both with and without SEN (Clark \& Peterson, 1986; JordanWilson \& Silverman, 1991; Marshall, 1992; Newman, Griffin, \& Cole, 1989; Scruggs \&

\footnotetext{
${ }^{1}$ In the absence of consensus on how to designate students with learning difficulties and/or disabilities, students at risk of failure, and those who struggle to learn for a variety of reasons, I use the British term students with special education needs (students with SEN) here. This recognizes, however, that special education need is a relative term that may be represented differently by policies and procedures in various jurisdictions, that it is controversial, and that it is not meant to imply a deviation from a supposed class "norm."
} 
Mastropieri, 1996). The SET project's task was to investigate whether teacher differences had a role in the success of included students.

To this day, inclusion continues to be a debatable concept. Internationally the debate has been characterized by multiple perspectives, some of them extreme. In its simplest form, inclusion is understood to be a physical placement (integration) of students who have been designated as having SEN into regular (mainstream) classrooms. More complex conceptions move beyond placement to define inclusion as meeting the social and academic needs of students with SEN in the regular classroom. Some define inclusion as meeting the social and academic needs of all students, and, at the most complex level, as creating communities that are based on "equity, care ..., justice, honouring of subjugated knowledge and valuing diversity" (Göransson \& Nilholm, 2014, p. 270). This last definition holds that the term inclusion should refer to all students as a community of practice, and not just to those who achieve outside an institutionally created "norm" (Botha \& Kourkoutas, 2016). The issue of how far the term inclusion should encompass all learners is still not without controversy, however (Dyson, 2014; Haug, 2014; Nilholm \& Göransson, 2017). It is clear, though, that the impact of inclusive classrooms must be considered for all students, and that teachers and their instructional styles are key to learning outcomes.

\section{How Do Teachers Deliver Instruction to Students in Inclusive Classrooms?}

Our first research question examines how and with whom teachers work in inclusive elementary classrooms and how their practices vary. The literature has confirmed that teaching quality had a major effect not only on students with SEN included in the regular classroom, but on all learners. In a meta-analysis of studies of teacher factors in inclusive classrooms, Hattie (2009) reported that teaching practices explain about $30 \%$ of the variance of student achievement.

More recent studies have shown that, in well managed inclusive classrooms, students without SEN are likely to be more engaged in learning, and to be more successful than in classrooms where teachers express concerns about inclusion. Szumski, Smogorzewska, and Karwowski (2017) conducted a meta-analysis of 47 studies to measure how the presence of students with special education needs impacted students without such needs. Their findings confirmed the weak but positive relationship between including students with SEN and overall benefits for students without SEN. Szumski et al. suggested that their findings show that there are not only social and academic benefits to inclusion for students with SEN, but also academic benefits for all students, both with and without SEN.

One of the studies reviewed by Szumski et al. (2017) was part of the SET project (Demeris, Childs, \& Jordan, 2007). In this large-scale study, the SET research team found positive effects on the Ontario provincial Grade 3 EQAO achievement scores among students attending classrooms that included students who had been formally designated

as exceptional. Contrary to prediction, in classes in which two or more students had been identified as exceptional in the Grade 3 classes, the overall achievement of the class as a whole was higher. Since class size and socio-economic status did not contribute to the finding, the results might be attributable to difference in teaching practices. It is possible that teachers who accepted students designated as exceptional, and who put them forward 
for the provincial tests, worked differently with their classes than those who either did not include students with exceptionalities or requested exemption for these students from the tests. The Demeris et al. study provided no proof of this possibility. The project team did find, however, considerable differences in teaching styles in other studies.

This leads to the second research question to be explored.

\section{How Do Teachers Work with Included Students with SEN and Students at Risk of School Failure?}

Since there is variation among how teachers work in inclusive classroom, are there styles of teaching or patterns of student engagement that are apparent with the included students with SEN, compared to students without SEN?

The Classroom Observation Scale (COS) was developed by Stanovich (1994; Stanovich \& Jordan, 1998) to measure how teachers in elementary classrooms were teaching their students both with and without SEN, and those at risk. The technical details of the COS are contained in a separate article in this issue (Jordan, 2018). The COS was based on Englert, Tarrant, and Mariage's (1992) synthesis of the teaching practices that had proved to be effective for enhanced student learning. This so called "process-product research" in the 1980s was designed to identify what teaching processes predicted student learning products or outcomes. While the process-product view of effective teaching was later criticized for being too narrowly focused on the mechanics of teaching, it did supply a body of research on the various characteristics of teachers' management and presentation styles that contributed to student outcomes. The first three sections of the COS reflect this work: Classroom Management; Time Management; and Lesson Presentation.

As the Supporting Effective Teaching (SET) project developed, new elements were added to the COS, including amplifying the items on lesson presentation to reflect scaffolding instruction, questioning techniques, and a new section on how teachers adapted instruction for students with SEN. Several items were identified as distinguishing more effective from less effective teachers: the Student Engagement score. A measure of Predominant Teaching Style was added to reflect the length and depth of teacher-student instructional interactions.

The COS was administered by two observers independently scoring core subject lessons (language arts, math, social studies) of 60 minutes or more, when the students with SEN were present in the classroom. Before the lesson began, the teacher marked a class list to identify which students had been formally designated as exceptional or as in need of an Individual Educational Plan (IEP), which students were of concern to the teacher as being at risk of failure, and which were designated as gifted. The students then either displayed a name tag on their desks, or wore name badges. Each observer selected two names to observe from the teacher's list, one exceptional or at risk, and one undesignated (typically achieving). The teacher was not told which students were being observed. Inter-rater reliability was assessed as the percentage correspondence of ratings of the two observers; ( $94 \%$ for two observers of 63 teachers, McGhie-Richmond, Underwood, \& Jordan, 2007). 
The COS proved to be a rich tool for differentiating teachers' practices. In the third section of the scale on lesson presentation, the observers checked off accommodations for individual students, small groups, and whole classes, such as teacher questioning that engages student in the concepts of the lesson, and prompting to cognitively extend the students' thinking. Over the course of more than 100 observations, my colleagues and I documented the variety of teachers' instructional styles. Some teachers packed a great deal of instruction into the time they had available with large and small groups and individual students. It seemed that, if both the class routines and instructional time were well managed, teachers were able to free instructional time to cognitively engage students both in large groups and individually, especially during seat work sessions and smallgroup activities. It is as if they have created "all the time in the world" to focus on calibrating instruction to the various levels of knowledge of students.

Student Engagement. This led to questions about which components of the COS distinguished the highest scoring teachers from the rest. A key question was whether quality teaching requires mastery of class management routines and time management (sections 1 and 2 of the COS), as a prerequisite for the instructional practices observed in the third section, such as questioning individuals and groups, extending student thinking, and scaffolding instruction. Do the three sections of the COS constitute a sequence of increasing skill, with classroom management and time management skills being prerequisite to lesson presentation?

A discriminant functions analysis of the scores of 63 regular classroom elementary school teachers on the 31 items of the COS (McGhie-Richmond, et al., 2007) determined that the highest scoring teachers did not show greater skills in lesson presentation, compared to their lower scoring peers. There were, however, five individual COS items from all three sections that did discriminate the total scores of highest scoring from midand lowest scoring teachers. These items collectively addressed how teachers engaged all their students in the lesson: telling students what to expect, gaining student attention, monitoring lesson transitions, maintaining high student response rates in teacher-led activities, and subject-related questioning. These five items became the Student Engagement score in subsequent studies.

Predominant Teaching Style. Lindsay (1995; Jordan, et al., 1997) recorded teachers' talk with individuals and small groups as they circulated around their classes during seat work. Further, the students interacting with the teacher were identified as SEN, at risk, or typically achieving. This provided a measure of the relative length and complexity of teachers' instructional interactions and styles of teaching that engaged each student; a sort of "student's eye view" of received instruction.

On the basis of these results, the team built into the final version of the COS a measure of teachers' talk with individual students as a supplement that we called Predominant Teaching Style. The observers scored the teacher's interactions with each of three tracked students: designated as exceptional, teacher-nominated as at risk, and normally achieving. Observers applied a 7-point scale to rate the length and complexity of each teacher-student interaction with the tracked students during the seat work part of a lesson. The lowest score on the Predominant Teaching Style scale is no observed interaction with the tracked students. Midpoints include teacher checks student work and 
moves on and teacher transmits instructions or asks a question but does not wait for a response. At the top rating, teacher elaborates, teachers interacted with individuals and small groups in the manner of turn-taking, engaging students in dialogue that extended the students' thinking at high levels of cognitive engagement. A dialogue included waiting for and responding to a student response. It was often a question-answer series of turns: teacher-student-teacher, or student-teacher-student. An interaction that met or exceeded even one turn-taking dialogue was allocated to this top category. While this was not a particularly dramatic indicator of instruction, it occurred sufficiently rarely to distinguish among the teachers and the groups of students with whom they worked. Social interactions unrelated to the lesson material were not included.

The Predominant Teaching Style rating provided the instructional interactions received from teachers by students in three groups, SEN, at risk, and typically achieving. These were added to the analysis of the COS index of effective instruction, proving to be highly correlated with the overall score on the $\operatorname{COS}(n=31 ; r=.77 ; p<.01)$. Teachers who scored high on the overall COS also scored high on Predominant Teaching Style: creating time for instructional engagement of individual students and small groups, and for engaging them in cognitively extending question-answer sessions. The COS total score, but more specifically the Predominant Teaching Style score, could therefore be viewed as an index of quality of instruction.

The subgroups of students who were designated as SEN as well as those typically achieving received more frequent instructional interactions from their high COS-scoring teachers than did students in the classrooms of lower COS-scoring teachers $(n=31$; $r=.37 ; p<.05)$. In other words, teachers with high scores on the overall COS provided more individual instructional attention for students who were both typically achieving and SEN. Students at risk, however, did not appear to benefit from increased individual instructional attention in all classrooms. This group received the least individual instructional time and attention overall.

With ample evidence that there are measurable differences among teaching practices and teachers' allocation of instructional time, the SET team turned to the questions of whether these differences in instructional practices were related to differences in teachers' beliefs about and attitudes toward inclusion, and about the learning needs of students.

\section{Do Teachers Differ in Their Beliefs About Students with SEN and About Who Is Responsible for Instruction?}

Differences in teachers' views on inclusion encompass beliefs about the learning characteristics of students and about who is responsible for instructing students with SEN. Differences in such views are related to differences in how teachers use their instructional time, with whom, and the types and complexity of the instruction they provide. Teachers' epistemological theories about ability and disability seem to be associated with their views about inclusion (Schwartz \& Jordan, 2011), and, SET researchers claim, with how they teach their students both with and without SEN in their classrooms. 
The Pathognomonic-Interventionist Interview. In the Lindsay (1995) study (Jordan et al., 1997; Stanovich \& Jordan, 2004) teachers who held the view that it is their responsibility to deliver instruction that meets the diverse needs of learners in their classes were also more able than their peers to meet the needs of all their students, including their students with SEN. The beliefs of the teachers were distinguished through the Pathognomonic-Interventionist Interview (Stanovich, 1994; Stanovich \& Jordan, 1998). Teachers who held pathognomonic ${ }^{2}$ beliefs indicated that it is the responsibility of special education-trained teachers and support workers and not regular classroom teachers to carry out the instruction of students with SEN. These teachers frequently claimed that the additional resources of special education, particularly on a withdrawal basis from the classroom, relieves them of the extra time required to work with included students with SEN, and allows them to increase their instructional time with students without SEN. Yet, when the scores of pathognomonic-rated teachers were compared with those of interventionist-rated teachers for instructional time, student engagement, and instructional interactions that promote higher order thinking skills, the interventionist teachers came out ahead. Teaching in a diverse, inclusive class seems to be about not only the amount of instructional time but how teachers organize and present the available time in order to meet a variety of learning needs simultaneously. Indeed, teachers who subscribe to inclusion use techniques such as peer coaching, co-operative groupings, Universal Design for Instruction, and differentiated instruction, and learning centres to create additional instructional time that can be spent with individual learners and small groups (Connor \& Cavendish, 2018). By designing instruction that students can selfdirect, the interventionist teachers seem to be able to focus attention on individual learner needs and to engage individuals and small groups of students in cognitively demanding tasks that are calibrated and scaffolded to the level of the students' understanding. Their style of teaching, as well as their allocation of time and their lesson preparation, differs markedly from those who do not see inclusion as their responsibility (Jordan, Glenn, \& McGhie-Richmond, 2010)

Investigating teachers' understanding of their roles and responsibilities in working with the students in their classrooms and documenting their teaching practices is crucial, therefore, to uncovering the elements of effective inclusion.

Engel (1993) noted that people create narrative accounts of their experiences, in part reconstructing the events they relate to reflect the beliefs and values they hold. Their autobiographical stories therefore may differ in varying degrees from the actual events that took place, but the recounting represents their realities. The narrator ties together events, and infuses the account with explanation, describing why such and such occurred and in what sequence. Engel (1993) noted that the retelling of events is "an act of insight, a reinterpretation of the past, a reaffirmation of core values and beliefs" (p. 792). Polkinghorne (1988) used such retelling of personal experiences as a research tool, with the aim of understanding the perspective of the narrator and the attributions of cause and effect in the events recounted.

\footnotetext{
${ }^{2}$ Pathognomonic beliefs focus on the pathological characteristics of a student with SEN, and view these as internal to the student, medically based, stable, and not affected by instruction.
} 
Using this technique in a confidential interview, SET researchers asked teachers to identify one or more students with SEN or at risk, with whom they had previously worked. They were asked to recount the events that took place over the course of a school year, from the first time they encountered the student until they completed the year or until the present. During the recounting, interviewers asked probe questions designed to elicit explanations of cause and attributions of responsibility, asking why and how the events took place, and who was involved. These explanatory statements formed the material that was analyzed to identify the beliefs of teachers about their role, and the roles of others in the progress of the students.

The result was the Pathognomonic-Interventionist (P-I) Interview. It places teacher beliefs about disability and about teachers' responsibility for instructing students along a dimension, from pathognomonic (naming the pathology, attributing learning difficulties to factors internal to the student), to interventionist (attributing difficulties to lack of opportunity to learn, lack of communication, environmental and social barriers).

The P-I Interview was scored on five topics: the teacher's initial information gathering and assessments, programming and instructional accommodations, monitoring and review of progress, communication with other staff and resource personnel, and communication with parents. An overall score was the sum of the five subscores. Further, raters selected a global rating for the extent that the teacher took responsibility for the student's instruction (Responsibility score) and a rating for the attributions that the teacher made about the reasons for the student's progress (Attribution score).

The P-I Interview is a powerful tool, avoiding the transparency of paper and pencil assessments of beliefs, and other forms of assessments that lead the respondent to seek socially desirable responses. Teachers tell their stories, recreating the events and the reasons behind them in a way that displays how they see their roles and responsibilities, and the roles of others, and to what they attribute student progress. More detail of the research technique and technical data are supplied in a subsequent article in this issue (Jordan, 2018).

The results of the P-I Interview indicate that teachers differ widely in how they view disability, its causes, and the locus of responsibility for instruction that results. About $25 \%$ of more than 100 teachers interviewed over the course of the project saw students with SEN from a pathognomonic or deficit perspective, as locked into their difficulties, and unlikely to make substantial progress as a result. They also tended to see such students as needing specialized instruction and services that were beyond the teachers' available time, resources, and expertise.

About $20 \%$ of teachers, on the other hand, expressed beliefs at the opposite end of the P-I scale: that students with SEN represented a challenge to communication that was the teacher's responsibility to solve, that could be overcome with resources and support, and that was a component of how instruction had to be designed and presented in their classrooms. They believed that they held the primary responsibility for instruction, including finding ways to calibrate instruction to the communicative, cognitive, and affective needs of their students. 
The remaining teachers, about half of the total sampled, could be characterized as holding beliefs that vacillated along the P-I scale. They frequently expressed frustration with their own lack of expertise, time, and supports, and with the attitudes and beliefs of resource people, colleagues, and others. They indicated that they held responsibility for meeting student learning needs but were at a loss as to how to deliver appropriate instruction without more supports, time, and training.

\section{Are Classroom Teaching Practices (COS Scores) Related to Teacher Beliefs About Disability and Instructional Responsibility (P-I Scores)?}

The third research question examined whether the variation of teaching practices had any connection to the variety of teacher beliefs that the P-I Interview revealed. The P-I summed score was entered into quantitative analyses to see whether there was a relationship between the COS scores (total score, Predominant Teaching Style, Student Engagement) and teacher beliefs about disability from the P-I Interview, (the P-I Interview total score, and Responsibility and Attribution ratings). Figure 1 presents the correlations between the scores and ratings of the P-I Interview (right column) and the teaching practices represented by the scale and ratings of the COS. Glenn (2007) conducted this analysis with 36 regular elementary teachers for whom there were both COS and P-I scores. While the P-I scores did not correlate with any of the main COS subscales, there were significant correlations between the subscales. The teachers' views about locus of responsibility correlated with the total COS score $(r(36)=.44, p<.05)$, Student Engagement $(r(36)=.43, p<.05)$, and Predominant Teaching Style $(r(36)=.43$, $p<.05)$. The scores for teachers' Attribution of the cause of learning difficulties correlated with Student Engagement $(r(36)=.40, p<.05)$, and with Predominant Teaching Style $(r(36)=.36, p<.05)$.

Figure 1. Relationships Between the Measures of Teaching Practices from the Classroom Observation Scale, with Measures from the P-I Interview

Teaching Practices

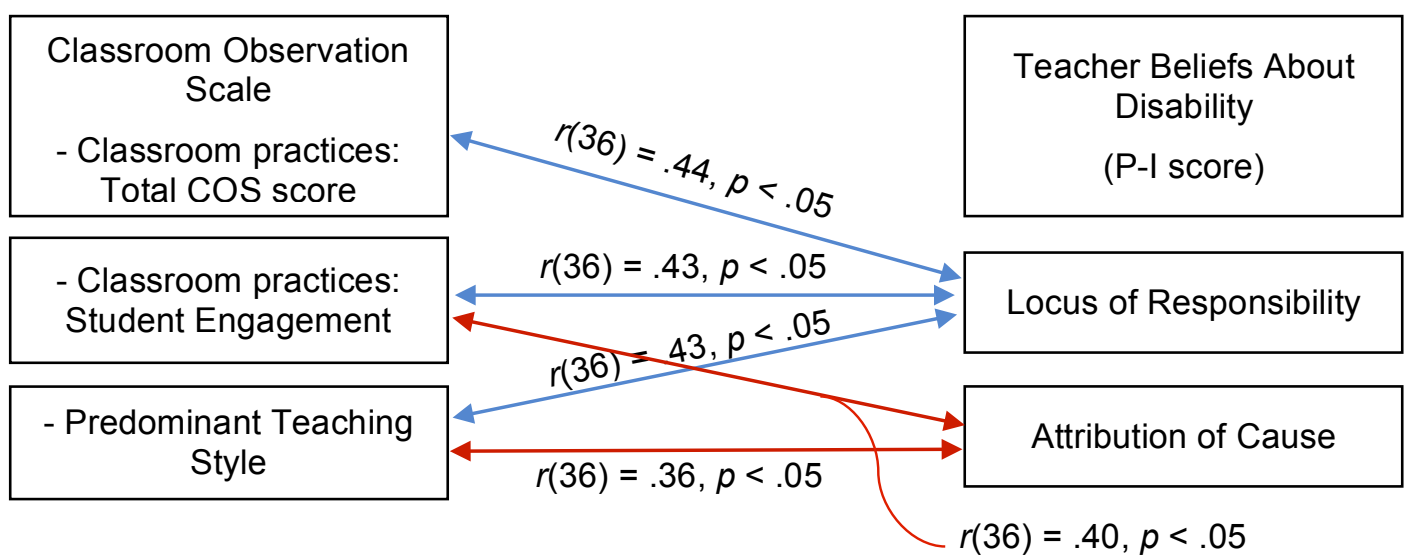

Note: Locus of Responsibility in blue, Attribution of Cause in red. 
It seems that the more teachers assume responsibility for instruction of students with SEN, and the more they view learning difficulties as the product of an environment that creates barriers for people with disabilities, the more they are likely to provide quality instruction to all their students.

Kiely, Brownell, Lauterbach, \& Benedict (2014) have suggested that assessments using standard techniques for measuring teaching beliefs, often by self-report, do not correspond with what teachers do in practice. Perhaps this is partly because research participants are savvy about how they are expected to respond on most questionnaires. The use of the P-I Interview as a measure of beliefs that infers beliefs from participants' retelling of events, together with observing practices directly in the classroom did, however, yield evidence that there is a moderate correlation between views that align with an interventionist perspective and high scores on teaching practices.

\section{Do Beliefs About the Nature of Disability Relate to Teachers' Broader Epistemological Beliefs About Ability and Whether It Is Fixed (Native) to Learners or the Product of Learning (Nurtured)?}

In an attempt to create a questionnaire version of the P-I Interview that would have low transparency but would also be more economical of time and labour to administer, Glenn (2007) created the Beliefs about Learning and Teaching Questionnaire (BLTQ). Stipek, Givvin, Samon, and McGyvers (2001) had developed the Beliefs about Mathematics and Teaching Scale (BMTS) to examine teachers' beliefs that mathematics ability is an entity trait or an incrementally acquired characteristic of learners. They examined whether such differences in beliefs relate to teachers' preferred practices in teaching mathematics. As in the Pathognomonic concept of disability at one end of the PI scale, an Entity view holds that ability is a fixed or nativist trait that is unchanging and internal to the individual. On the other hand, like the Interventionist concept of disability in the P-I scale, the Increment end of the BLTQ scale posits that ability can be nurtured and developed, and is influenced by opportunity to learn in response to environmental factors such as teaching. The Entity-Increment (E-I) dimension is therefore an attempt to uncover the underlying epistemological beliefs of teachers. It also follows that the underlying assumptions about disability as fixed or fluid in the P-I score may be a component of a teacher's broader epistemological beliefs about ability.

Items in the BLTQ asked teachers to agree or disagree with statements about the entity (fixed) nature compared to the fluid, acquired nature of mathematics ability:

"The ability to learn is something people have a certain amount of and there isn't much they can do to change it." (fixed).

"Students can be taught learning strategies to overcome learning disabilities." (fluid).

Following factor analysis of responses of 32 teachers to the BLTQ prototype, the E-I items formed one factor along with three other factors labelled Teacher-Controlled Instruction, Student-Centred Instruction, and Attaining Standards. As a group, the E-I items had an eigenvalue of 1.76 and accounted for $8.82 \%$ of the variance in teachers' responses. The development and characteristics of the BLTQ measure are described in detail in the paper by Glenn (2018) in this issue. 
This phase of the research set out to test the hypothesis that the teachers' views of ability as fixed or fluid was related to their views about disability as internal and pathological rather than created by environmentally sources and communication barriers. The correlation of the P-I beliefs from the P-I Interview with E-I beliefs from the BLTQ for 32 teachers was $r(32)=.37, p<.05$. It therefore appears that teachers who hold pathognomonic beliefs about disability also tend to hold the view that an individual's ability is fixed, and that there isn't much that can be done to change it. The alternative perspective was also apparent from the results. Teachers who believed that students with SEN can learn also claimed that overcoming barriers to learning is partly the responsibility of teachers. This nurture perspective also holds that ability is flexible and is largely influenced by the student being given the opportunity to learn.

\section{If Teacher Beliefs About Disability and Ability Are Related, Do They Both Influence the Practices that Teachers Use in Their Inclusive Classrooms?}

Kiely et al. (2014) noted the disconnect between what teachers say they believe about inclusion and diversity and what they actually do in their classrooms. In order to uncover whether the epistemology beliefs of teachers about ability and disability is related to how they teach, the SET team examined the correlations between the E-I, P-I, and COS scores of 36 teachers. The higher teachers' scores on the BLTQ for increment beliefs, the higher their COS Student Engagement scores $(r(36)=.38, p<.05)$. The evidence was not strong, but there was sufficient correlation to suggest that teachers who view ability as a fluid and acquired trait, and disability as having characteristics that can be circumvented or overcome with instruction, also tend to be more likely to deliver instruction that engages all their students in learning.

Interestingly, it was the teachers who held increment views of ability who also put more time into engaging their students at risk $(r(36)=.35, p<.05)$.

In Figure 2 the relationships between the measures are presented. Teaching practices are represented by the three scales in the lower left corner: total COS score; the Student Engagement score derived from five items that discriminated higher scoring from lower scoring teachers; and the Predominant Teaching Style score, a measure of the extent to which teachers engaged individual students and small groups in extended dialogues during seat work.

Teacher beliefs are represented by two sets of measures. On the top left of Figure 2 is the P-I Interview score of the teachers' views about disability as fixed or malleable; the Locus of Responsibility score, which is the interviewers' rating of the teachers' views of who holds the instructional responsibility for students with SEN; and the Attribution of Cause score, concerning the causes to which the teacher attributed learning difficulties.

On the top right of Figure 2 is the paper-and-pencil measure of teacher beliefs about the fixed or malleable nature of ability, the Entity-Increment score of BLTQ. As described above, the E-I score reflects some of the P-I score's focus on whether disability, and in the case of the E-I score, ability, are fixed and unresponsive to instruction (often termed the medical model), or are malleable and responsive to instruction and learning. The BLTQ also contains a measure of teachers' instructional 
preferences, a scale that reflects the teachers' preferences for a teacher-controlled or student-centred approach to learning.

When added to the data in Figure 1, Figure 2 shows that the beliefs ratings derived from the paper-and-pencil BLTQ are not as powerful as the P-I scores in predicting teaching practices. There is a modest correlation between the P-I and BLTQ scores, suggesting that there is an underlying belief about both ability and disability as fixed or malleable, validating the construction of the scales. The Responsibility score indicating the teachers' beliefs about the locus of teaching responsibility also correlates with the score for student-centered teaching, a factor indicating who controls instruction, and whether or not the teacher prefers to have students direct their own learning.

Figure 2: Relationships Between Teacher Beliefs and Teaching Practices

Teacher Beliefs

(P-I Interview)

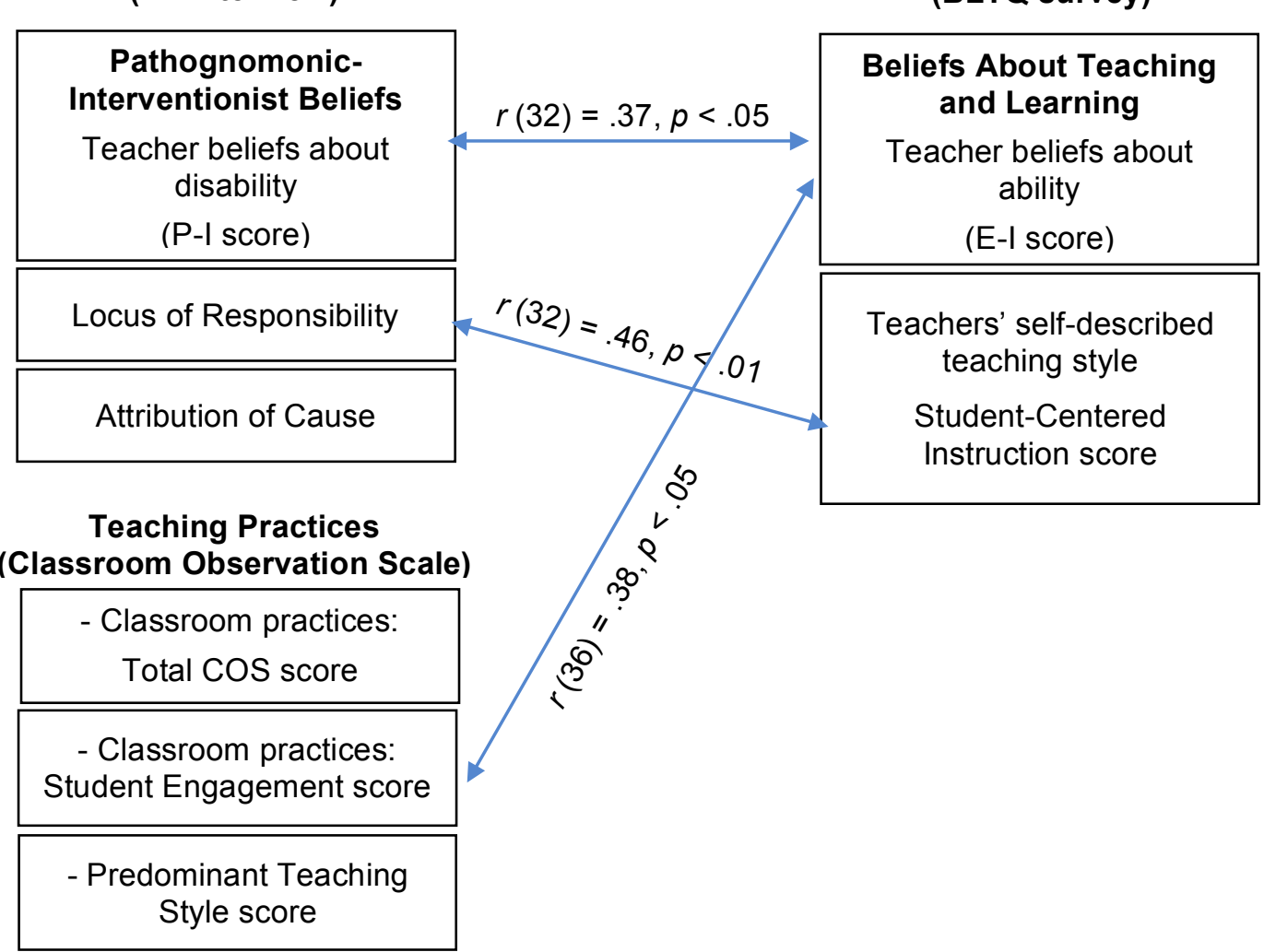

Teacher Beliefs

(BLTQ survey)

liefs About Teaching
and Learning
eacher beliefs about
ability
(E-I score)
achers' self-described
teaching style
Student-Centered
Instruction score

Note: Teacher beliefs from P-I Interview and BLTQ; teaching practices from COS score and ratings.

The main correlation between the measures of teaching practices and teacher beliefs from the BLTQ is shown between the student engagement score of the COS (the items that mark how successfully the teacher engages students) and the E-I score of the BLTQ. That is, teachers who reach the higher levels of practice as evidenced by their scores on the student engagement variable also believe that ability is something that can be fostered through learning. Further evidence for this trend in teachers' epistemological beliefs and 
their instructional practices did not emerge from the other scores and ratings. If added to the results shown on Figure 1, however, there is moderately strong evidence of a relationship between teachers' beliefs about disability and ability, and their choice of instructional practices.

\section{What Might Be the Origins of Teachers' Beliefs About Disability and About Their Roles and Responsibilities for Students with SEN?}

A number of important questions remain after applying the model of teacher beliefs and practices to current classrooms. SET research has provided preliminary evidence for some of these.

A. Are the prevailing views of the staff and administrators in the school influential in the beliefs of individual teachers about inclusion?

Dyson, Polat, and Farrell (2004) have suggested that effective schools develop an "ecology of inclusion" (p. 14). Early in the SET project, Stanovich (1994; Stanovich \& Jordan, 1998) interviewed principals as well as teachers and resource teachers, using the P-I Interview as a measure of beliefs about including students with SEN in regular elementary classrooms, and about staff roles and responsibilities for instructing them. While more research is needed to examine this, there was clear evidence that the views of the principal correlated with those of their staffs $(r=.50 ; p<.05)$. Stanovich coined the term school norm to indicate that a school staff often held beliefs about their roles and responsibilities that were internally consistent. Perhaps the carry-over of collective beliefs is a function of the leadership in a school, as Dyson et al. (2004) suggest.

B. How stable are teachers' beliefs about disability and about their responsibilities for working with students with SEN?

Attempts to track changes in teacher beliefs using the P-I Interview and other measures were largely unsuccessful. SET research did not find a correlation between years of teaching experience and P-I scores, for example.

White (2007) followed four teachers for five years from the inception of an initiative in their school board to implement inclusive practices to an exit interview after they had received considerable school-system-level and school-level in-service training and support to increase their inclusive practices. Three of the teachers began the project with high pathognomonic ratings, and despite the attention given to their practices, they exited the project with very little change in their beliefs as expressed by their stories in the final P-I interview. One teacher, the mother of a child with SEN, commenced the project with P-I Interview scores midway between P and I. After 5 years, this teacher described strong interventionist beliefs and practices, and had assumed a leadership role in the school system for advancing inclusion.

It appears that teacher beliefs can be resistant to forms of professional development and policy initiatives that are the mainstay of change mechanisms in school systems. More recent research has addressed how teachers in training might be exposed to alternative conceptions of disability, learning, and instruction (e.g. Lanterman \& Applequist, 2018). It is not yet clear how and when beliefs are formed, and how they can be challenged by policy or experience. There is some indication (Robinson, 2007; White, 
2007) that teachers who have experienced disabilities, either first-hand or through a close family member, are more likely to hold interventionist beliefs about the students in their classrooms.

Ultimately research needs to determine how teacher differences impact the progress and achievement of students both with and without SEN.

C. What can be done to change the beliefs of teacher candidates and early-career teachers?

If teacher beliefs are entrenched fairly early in their careers and are resistant to change, as White's (2007) study suggests, then addressing the beliefs of teachers in their training and early career years may be important. One hint from SET research is that teachers who have experienced disability in their own families are more likely to take an interventionist perspective in their classrooms. Perhaps all teacher candidates might benefit from a structured practical exposure to students with SEN as part of their training. Such a process might include tackling teacher trainees' assumptions about the fixed or malleable nature of ability and disability, and their impact on how teaching and learning proceed as a result. It may also be important to engage students in a dialogue about the fixed or malleable nature of ability and disability, and how they relate to the specific learning needs of students. The current testing practices for identifying disability as a variant from a norm contribute little to teachers' skills in meeting the learning needs of students.

Training already emphasizes good instructional practice that diversifies instruction and calibrates it to the levels of each students' understanding. For example, most teacher candidates can describe Vygotsky's (1978) zone of proximal development, although how this translates into action is less clear. Good practice that reflects how to implement Universal Design for Learning, differentiated instruction, and co-operative learning needs to be modelled and supported in practicum and practice teaching.

There is a need to get across to policy makers that an inclusive teaching style benefits all students in the classroom. There is now substantial evidence that inclusion based on effective teaching, is beneficial to learning at all levels of the school system.

Finally, SET research suggests that further study is needed to identify why students who are at risk within the inclusive classroom are falling between the cracks, even in the classrooms of teachers committed to inclusion.

\section{Discussion}

Some of the growing body of evidence is presented here to show that effective inclusion involves quality teaching and enhanced opportunities to learn for all students, including those who are formally designated as exceptional and those at risk of school failure. The studies reported above confirm the relationship between teaching practices and opportunity for students to learn. Despite continued complaints that inclusion detracts from the time that teachers spend with more able students, the evidence from the SET project adds to the growing literature that shows how effective instruction rather than placement per se results in greater opportunity to learn for all students, despite the variations in their educational needs. 
The more simplistic notion of inclusion as placement seems to have little or no predictive value. Strategies for adapting instruction for students with SEN, however, do have an impact. These include controlling task difficulty, co-operative learning, teaching in small groups, calibrating instruction to students' individual levels of understanding through directed response questioning, and providing frequent feedback (Vaughn, Gersten, \& Chard, 2000). Similarly, an instructional focus on concepts and big ideas, and a positive classroom climate and sensitive teachers have been confirmed in numerous studies and meta-analyses to work effectively in inclusive classrooms (Hattie, 2009; Mitchell, 2014). Connor \& Cavendish (2018) confirmed that high school students reflected such instructional practices in evaluating what made for successful inclusion from their perspectives.

There is considerable diversity among the teachers themselves in what they believe about ability and disability and about their roles and responsibilities for the students included in their classrooms. Effective teachers hold systematic beliefs about their roles and their responsibilities, and about their students' abilities and disabilities, that differentiates them from less effective teachers. They believe that they are responsible for meeting student needs, and that disabilities are in part caused by barriers to communication and access that they are responsible for dismantling. Such beliefs about roles and responsibilities with students with disabilities also extend to beliefs about ability in general.

Ultimately some teachers view disability as a deficiency located within students, a permanent and indelible characteristic that defines the student. At a simplistic level, these students with SEN are seen as unable to benefit from the instruction and support that is offered to students without SEN. They are therefore seen to be somehow less worthy of instruction than those students whom the teacher views as more likely to benefit. When this is paired with a teaching style that broadcasts to the median of the class, it is inevitable that some students do not learn.

On the other hand, teachers who view disability as a challenge to communicating ideas and expressing responses are more readily willing to use a variety of teaching styles to circumvent communication barriers and to accommodate differences, and to use multiple means of communication and instruction to bring students with SEN into the learning community. Early in the project, the SET project confirmed that teacher practices with students with SEN has an effect on how much instructional support and level of cognitive engagement is received by all students, including those not designated as having SEN (Jordan et al., 1997; Jordan \& Stanovich, 2003, 2004). By the end of the project SET research had confirmed the importance of engaging all students in learning, and in developing higher order thinking skills (Jordan, et al., 2010; Jordan \& McGhieRichmond, 2014).

Numerous instructional methods have been suggested in recent years to accommodate diverse student needs: co-operative learning, co-teaching, differentiated instruction, constructivist techniques, Universal Design for Learning, and universal access to curriculum. Underlying these methods, however, there needs to be a will on the part of teachers to understand that using them has benefits for all students. Without a corresponding change in the epistemological beliefs of some teachers and in their beliefs 
about their roles and responsibilities in working with students with SEN in inclusive classrooms, there cannot be a will to acquire different instructional techniques and to engage all students in instruction.

Although the presence of students with SEN in regular classrooms has been shown to benefit the achievement of students without SEN, and despite the evidence that teaching method, teacher attitudes, and beliefs about inclusion rather than instructional time contribute to the differences, this finding seldom leads to changes in the organization of the school, its curriculum and resources, and instructional strategies (Ainscow, Booth \& Dyson, 2006; Ainscow, Dyson, Goldrick \& West, 2012; Giangreco $\&$ Suter, 2015). Although inclusive education could be understood as transformative for the delivery of education, this has yet to be taken up in practice.

\section{References}

Ainscow, M., Booth, T., \& Dyson, A. (2006). Improving schools, developing inclusion. London, UK, and New York, NY: Routledge

Ainscow, M., Dyson, A., Goldrick, S., \& West, M. (2012). Making schools effective for all: Rethinking the task. School Leadership and Management, 32(3), 119-123. doi:10.1080/13632434.2012.669648

Botha, J., \& E. Kourkoutas. (2016). A community of practice as an inclusive model to support children with social, emotional and behavioural difficulties in school contexts. International Journal of Inclusive Education, 20(7), 784-799.

Clark, C. M., \& Peterson, P. L. (1986). Teachers' thought processes. In M. Wittrock (Ed.). Handbook of research on teaching (3rd ed., pp. 255-296). New York, NY: MacMillan.

Connor, D. J., \& Cavendish, W. (2018). 'Sit in my seat': Perspectives of students with learning disabilities about teacher effectiveness in high school inclusive classrooms. International Journal of Inclusive Education. Online publication 18 Apr 2018. doi:10.1080/13603116.2018.1459888

Demeris, H., Childs, R., \& Jordan, A. (2007). The influence of students with special needs included in Grade 3 classrooms on the large-scale achievement scores of students without special needs. Canadian Journal of Education, 30(3), 609-627.

Dyson, A. (2014). A response to Göransson and Nilholm. European Journal of Special Needs Education, 29(3), 281-282. doi:10.1080/08856257.2014.933542

Dyson, A., Polat, F., \& Farrell, P. (2004, April). Inclusion and student achievement. Paper presented at the annual meeting of the American Educational Research Association, San Diego, CA.

Engel, M. (1993). Origin myths: Narratives of authority, resistance, disability and law. Law and Society, 27, 785-826.

Englert, C. S., Tarrant, K. L., \& Mariage, T. V. (1992). Defining and redefining instructional practices in special education: Perspectives on good teaching. Teacher Education and Special Education, 15, 62-86.

Giangreco, M. F., \& Suter, J. C. (2015). Precarious or purposeful? Proactively building inclusive special education service delivery on solid ground. Inclusion, 3, 112-131.

Glenn, C. (2007). The impact of teachers' epistemological beliefs and their beliefs about disability on their teaching practices in inclusive classrooms (Unpublished Ph.D. dissertation). University of Toronto, Toronto, ON. 
Glenn, C. V. (2018). The measurement of teacher's beliefs about ability: Development of the Beliefs About Learning and Teaching Questionnaire. Exceptionality Education International, 28(3), 51-66.

Göransson, K., \& Nilholm, C. (2014). Conceptual diversities and empirical shortcomings-A critical analysis of research on inclusive education. European Journal of Special Needs Education, 29(3), 265-280. doi:10.1080/08856257.2014.933545

Hattie, J. A. C. (2009). Visible learning. A synthesis of over 800 meta-analyses relating to achievement. London, UK: Routledge.

Haug, P. (2014). Empirical shortcomings? A comment on Kerstin Göransson and Claus Nilholm, 'Conceptual diversities and empirical shortcomings-A critical analysis of research on inclusive education.' European Journal of Special Needs Education, 29(3), 283-285. doi:10.1080/08856257.2014.933548

Jordan, A. (2018). The Supporting Effective Teaching project: 2. The measures. Exceptionality Education International, 28(3), 28-50.

Jordan, A., Glenn, C., \& McGhie-Richmond, D. (2010). The Supporting Effective Teaching (SET) project: The relationship of inclusive teaching practices to teacher beliefs about disability and ability, and about their roles as teachers. Teaching and Teacher Education: An International Journal of Research and Studies, 26(2), 259-266.

Jordan, A., Lindsay, L., \& Stanovich, P. (1997). Classroom teachers' interactions with students who are normally achieving, at-risk and exceptional. Remedial and Special Education, 18(2), 82-93.

Jordan, A., \& McGhie-Richmond, D., (2014). Identifying effective teaching practices in inclusive classrooms. In C. Forlin \& T. Loreman (Eds.), International Perspectives on Inclusive Education: Vol. 3. Measuring inclusive education (pp.133-162). Bingley, UK: Emerald Group Publishing. doi:10.1108/S1479-363620140000003023

Jordan, A., \& Stanovich, P. (2003). Teachers' personal epistemological beliefs about students with disabilities as indicators of effective teaching practices. Journal of Research in Special Educational Needs. [Online], 3. Retrieved from http://www.nasen.org.uk

Jordan, A., \& Stanovich, P. (2004). The beliefs and practices of Canadian teachers about including students with special needs in their regular elementary classrooms. Exceptionality Education Canada, 14(2-3), 25-46.

Jordan-Wilson, A., \& Silverman, H. (1991). Teachers' assumptions and beliefs about the delivery of services to exceptional children. Teacher Education and Special Education, 14, 198-206.

Kauffman, J. M. (1981). Introduction: Historical trends and contemporary issues in special education in the United States. In J. M. Kauffman \& D. P. Hallahan, (Eds.), Handbook of special education (pp. 3-23). Englewood Cliffs, NJ: Prentice Hall.

Kauffman, J. M., \& Hallahan, D. P. (Eds.). (2005). The illusion of full inclusion: A comprehensive critique of a current special education bandwagon (2nd ed.). Austin, TX: PRO-ED

Kiely, M. T., Brownell, M. T., Lauterbach, A. A., \& Benedict, A. E., (2014). Teachers' beliefs about students with special needs and inclusion. In H. Fives \& M. G. Gill, (Eds.), International handbook of research on teacher beliefs (pp. 475-490). New York, NY: Routledge.

Lanterman, C. S., \& Applequist, K. (2018). Pre-service teachers' beliefs: Impact of training in Universal Design for Learning. Exceptionality Education International, 28(3), 102-121.

Lindsay, L. S. (1995). The relationship between teacher beliefs and teacher-student conversational interactions in the mainstream classroom setting (Unpublished Ph.D. dissertation). University of Toronto, Toronto, ON. 
Jordan

Marshall, H. (1992). Seeing, redefining and supporting student learning. In H. Marshall (Ed.). Redefining student learning: Roots of educational change (pp. 1-32). Norwood, NJ: Ablex.

Mitchell, D., (2015). Inclusive education is a multi-faceted concept. CEPS Journal 5(1), S. 9-30.

McGhie-Richmond, D., Underwood, K., \& Jordan, A. (2007). Developing effective instructional strategies for teaching in inclusive classrooms. Exceptionality Education Canada, 17(1-2), $27-52$.

Newman, D., Griffin, P., \& Cole, M. (1989). The construction zone: Working for positive gains in schools. Cambridge, UK: Cambridge University Press.

Nilholm, C., \& Göransson, K. (2017). What is meant by inclusion? An analysis of European and North American journal articles with high impact. European Journal of Special Needs Education, 32(3), 437-451. doi:10.1080/08856257.2017.1295638

Polkinghorne, D. E. (1988). Narrative knowing and the human sciences. Albany, NY: State University of New York Press.

Robinson, P. (2007). The characteristics of teacher expertise in elementary school inclusive classrooms (Unpublished Ed.D. dissertation). University of Toronto, Toronto, ON.

Scruggs, T. E., \& Mastropieri, M. A. (1996). Teacher perceptions of mainstreaming/inclusion, 19581995: A research synthesis. Exceptional Children, 63(1), 59-74.

Schwartz, E., \& Jordan, A., (2011). Teachers' epistemological beliefs and practices with students with disabilities and at-risk in inclusive classrooms: Implications for teacher development. In J. Brownlee, G. Schraw, \& D. Berthelsen (Eds.), Personal epistemology in teacher education (pp. 210-226). London, UK: Routledge Falmer.

Stanovich, P. J. (1994). Teachers' sense of efficacy, beliefs about practice, and teaching behaviours as predictors of effective inclusion of exceptional and at risk pupils (Unpublished doctoral dissertation). University of Toronto, Toronto, ON.

Stanovich, P., \& Jordan, A. (1998). Canadian teachers' and principals' beliefs about inclusive education as predictors of effective teaching in heterogeneous classrooms. Elementary School Journal, 98(3), 221-238.

Stanovich, P., \& Jordan, A. (2004). Inclusion as professional development. Exceptionality Education Canada, 14(2-3), 169-188.

Stipek, D. J., Givvin, K. B., Samon, J. M., \& McGyvers, V. L. (2001). Teachers' beliefs and practices related to mathematics instruction. Teaching and Teacher Education, 17, 213-226.

Szumski, G., Smogorzewska, J., \& Karwowski, M. (2017). Academic achievement of students without special educational needs in inclusive classrooms: A meta-analysis. Educational Research Review 21, 33-54.

Vaughn, S., Gersten, R., \& Chard, D. J. (2000). The underlying message in LD intervention research: Findings from research syntheses. Exceptional Children, 67, 99-114.

Vygotsky, L. S. (1978). Mind and society: The development of higher mental processes. Cambridge, MA: Harvard University Press (original works published in Russian in 1930, 1933, 1935).

White, R. (2007). Characteristics of classroom teachers which contribute to their professional growth in implementing their inclusive classroom practices (Unpublished M.A. thesis). University of Toronto, Toronto, ON.

\section{Author's Note}

Correspondence concerning this article should be addressed to Anne Jordan, Ph.D., Department of Curriculum, Teaching and Learning, Ontario Institute for Studies in Education, 252 Bloor St. W., Toronto, ON, M5S 1V6, Canada. Email: anne.jordan@utoronto.ca 